\title{
Second-order composed contingent epiderivatives and set-valued vector equilibrium problems
}

\author{
Qilin Wang ${ }^{1 *}$, Zhi Lin ${ }^{1}$, Jing Zeng ${ }^{2}$, Zaiyun Peng ${ }^{1}$ and Xiaobing Li ${ }^{1}$
}

${ }^{*}$ Correspondence:

wangq197@126.com

${ }^{1}$ College of Sciences, Chongqing

Jiaotong University, Chongqing,

400074, China

Full list of author information is

available at the end of the article

\begin{abstract}
In this paper, we introduce the concept of a second-order composed contingent epiderivative for set-valued maps and discuss some of its properties. Then, by virtue of the second-order composed contingent epiderivative, we establish second-order sufficient optimality conditions and necessary optimality conditions for the weakly efficient solution of set-valued vector equilibrium problems with unconstraints and set-valued vector equilibrium problems with constraints, respectively.

MSC: $90 \mathrm{C} 46 ; 91 \mathrm{~B} 50$

Keywords: set-valued vector equilibrium problems; second-order composed contingent epiderivatives; weakly efficient solutions; second-order optimality conditions
\end{abstract}

\section{Introduction}

The vector equilibrium problem, which contains vector optimization problems, vector variational inequality problems and vector complementarity problems as special case, has been studied (see [1-14]). But so far, most papers focused mainly on the existence of solutions and the properties of the solutions, there are a few papers which deal with the optimality conditions. Giannessi et al. [15] turned the vector variational inequalities with constraints into another vector variational inequalities without constraints. They gave the sufficient conditions for the efficient solution and the weakly efficient solution of the vector variational inequalities in finite dimensional spaces. Morgan and Romaniello [16] gave the scalarization and Kuhn-Tucker-like conditions for weak vector generalized quasivariational inequalities in Hilbert space by using the subdifferential of the function. Gong [17] presented the necessary and sufficient conditions for the weakly efficient solution, the Henig efficient solution and the superefficient solution for vector equilibrium problems with constraints under the condition of cone-convexity. Qiu [18] presented the necessary and sufficient conditions for globally efficient solutions of vector equilibrium problems under generalized cone-subconvexlikeness. Gong and Xiong [19] weakened the convexity assumption in [17] and obtained the necessary and sufficient conditions for weakly efficient solutions of vector equilibrium problems. Under the nearly cone-subconvexlikeness, Long et al. [20] obtained the necessary and sufficient conditions for the Henig efficient solution and the superefficient solution to the vector equilibrium problems with constraints. By using the concept of Fréchet differentiability of mapping, Wei and Gong [21] obtained

(2014 Wang et al.; licensee Springer. This is an Open Access article distributed under the terms of the Creative Commons Attribution License (http://creativecommons.org/licenses/by/2.0), which permits unrestricted use, distribution, and reproduction in any medium, provided the original work is properly cited. 
the Kuhn-Tucker optimality conditions for weakly efficient solutions, Henig efficient solutions, superefficient solutions and globally efficient solutions to the vector equilibrium problems with constraints. Ma and Gong [22] obtained the first-order necessary and sufficient conditions for the weakly efficient solution, the Henig efficient solution, and the globally proper efficient solution to the vector equilibrium problems with constraints.

It is well known that the second-order tangent sets and higher-order tangent sets introduced in [23], in general, are not cones and convex sets, there are some difficulties in studying second-order and higher-order optimality conditions for general set-valued optimization problems. Until now, there are some papers to deal with higher-order optimality conditions by virtue of the higher-order derivatives or epiderivatives introduced by the higher-order tangent sets (see [24-32]). However, as far as we know the second-order optimality conditions of the solutions remain unstudied in set-valued vector equilibrium problems.

Motivated by the work reported in [22, 24, 26-31,33], we introduce a new secondorder derivative called second-order composed contingent epiderivative for set-valued maps and obtain some of its properties. By virtue of the second-order composed contingent epiderivative, we obtain second-order sufficient optimality conditions and necessary optimality conditions for the weakly efficient solution of set-valued vector equilibrium problems.

The rest of the paper is organized as follows. In Section 2, we recall some notions. In Section 3, we introduce second-order composed contingent epiderivatives for set-valued maps and discuss some of its properties. In Section 4, we establish second-order necessary and sufficient optimality conditions for weakly efficient solutions to set-valued vector equilibrium problems.

\section{Preliminaries and notations}

Throughout this paper, let $X, Y$, and $Z$ be three real normed spaces, $Y^{*}$ and $Z^{*}$ be the topological dual spaces of $Y$ and $Z$, respectively. $0_{X}, 0_{Y}$ and $0_{Z}$ denote the origins of $X$, $Y$, and $Z$, respectively. Let $C \subset Y$ and $D \subset Z$ be closed convex pointed cones in $Y$ and $Z$, respectively. Let $M$ be a nonempty subset in $Y$. The cone hull of $M$ is defined by cone $(M)=$ $\{t y \mid t \geq 0, y \in M\}$. Let $C^{*}$ be the dual cone of cone $C$, defined by

$$
C^{*}=\left\{y^{*} \in Y^{*}: y^{*}(c) \geq 0 \text {, for all } c \in C\right\}
$$

Let $E$ be a nonempty subset of $X, G: E \rightarrow 2^{Z}$ be a set-valued map. The domain, the graph and the epigraph of $G$ are defined, respectively, by

$$
\begin{aligned}
& \operatorname{dom}(G)=\{x \in E \mid G(x) \neq \emptyset\} \\
& \operatorname{graph}(G)=\{(x, z) \in X \times Z \mid x \in E, z \in G(x)\} \\
& \operatorname{epi}(G)=\{(x, z) \in X \times Z \mid x \in E, z \in G(x)+C\} .
\end{aligned}
$$

Denote

$$
G(E)=\bigcup_{x \in E} G(x) \quad \text { and } \quad\left(G-z_{0}\right)(x)=G(x)-\left\{z_{0}\right\}
$$


Definition 2.1 (see [33, 34]) A set-valued map $W: X \rightarrow 2^{Y}$ is said to be

(i) strictly positive homogeneous if

$$
W(\alpha x)=\alpha W(x), \quad \forall \alpha>0, \forall x \in X
$$

(ii) subadditive if

$$
W\left(x_{1}\right)+W\left(x_{2}\right) \subseteq W\left(x_{1}+x_{2}\right)+C
$$

Definition 2.2 (see [34,35]) Let $E \subset X$ be a nonempty convex set and $G: E \rightarrow 2^{Z}$ be a setvalued map with $G(x) \neq \emptyset$, for all $x \in E$. $G$ is said to be $D$-convex on $E$, if for any $x_{1}, x_{2} \in E$ and $\lambda \in(0,1)$,

$$
\lambda G\left(x_{1}\right)+(1-\lambda) G\left(x_{2}\right) \subseteq G\left(\lambda x_{1}+(1-\lambda) x_{2}\right)+D .
$$

Let $X$ be a normed space supplied with a distance $d$ and $K$ be a subset of $X$. We denote by $d(x, K)=\inf _{y \in K} d(x, y)$ the distance from $x$ to $K$, where we set $d(x, \emptyset)=+\infty$.

Definition 2.3 (see $[23,36]$ ) Let $K$ be a nonempty subset of $X$ and $x \in K, u \in X$. The contingent cone of $K$ at $x$ is

$$
T(K, x):=\left\{v \in X \mid \exists t_{n} \downarrow 0, \exists v_{n} \rightarrow v \text {, such that } x+t_{n} v_{n} \in K, \forall n \in N\right\} .
$$

Proposition 2.1 (see [36]) Let $K \subseteq X$ and $x \in K$. The following statements are equivalent:

(i) $u \in T(K, x)$;

(ii) there exist sequences $\left\{\lambda_{n}\right\}$ with $\lambda_{n} \rightarrow+\infty$ and $\left\{x_{n}\right\}$ with $x_{n} \in K$ and $x_{n} \rightarrow x$ such that $\lambda_{n}\left(x_{n}-x\right) \rightarrow v$.

Proposition 2.2 (see [23]) Let $K \subseteq X$ and $x \in K$. Then $T(K, x)$ is a closed cone.

Proposition 2.3 (see [37]) Let $K \subseteq X$ be a convex set, $x \in K$, and $u \in T(K, x)$. Then

$$
T(T(K, x), u)=\operatorname{clcone}(\operatorname{cone}(K-x)-u) .
$$

Let $E$ be a nonempty subset of $X, F: E \times E \rightarrow 2^{Y}$ be a set-valued bifunction, $F\left(x_{1}, x_{2}\right) \neq \emptyset$, for all $x_{1}, x_{2} \in E$. We suppose that $0_{Y} \in F(x, x)$, for any $x \in E$.

Let $x_{0} \in E$ be given. $F_{x_{0}}: E \rightarrow 2^{Y}$ is the set-valued map defined by

$$
\operatorname{graph}\left(F_{x_{0}}\right)=\left\{(x, y) \in E \times Y: y \in F\left(x_{0}, x\right)\right\} .
$$

The set

$$
\operatorname{epi}\left(F_{x_{0}}\right)=\left\{(x, y) \in E \times Y: y \in F\left(x_{0}, x\right)+C\right\}
$$

is called the epigraph of $F_{x_{0}}$. Denote

$$
F_{x_{0}}(E)=F\left(x_{0}, E\right)=\left\{y \in F\left(x_{0}, x\right): x \in E\right\} .
$$


Let $G: E \rightarrow 2^{Z}$ be a set-valued map with $G(x) \neq \emptyset$, for all $x \in E$.

In this paper, we consider the set-valued vector equilibrium problem with unconstraints (USVVEP): find $x_{0} \in E$ such that

$$
F\left(x_{0}, x\right) \cap\left(-A_{0}\right)=\emptyset, \quad \text { for all } x \in E,
$$

where $A_{0}=A \backslash\left\{0_{Y}\right\}, A$ is a convex cone in $Y$.

We also consider the set-valued vector equilibrium problem with constraints (CSVVEP): find $x_{0} \in K$ such that

$$
F\left(x_{0}, x\right) \cap\left(-A_{0}\right)=\emptyset, \quad \text { for all } x \in K,
$$

where $A_{0}=A \backslash\left\{0_{Y}\right\}, A$ is a convex cone in $Y$, and $K:=\{x \in E: G(x) \cap(-D) \neq \emptyset\}$.

Definition 2.4 Let int $C \neq \emptyset$.

(i) A vector $x_{0} \in E$ is called a weakly efficient solution of (USTVEP) if

$$
F\left(x_{0}, E\right) \cap(-\operatorname{int} C)=\emptyset .
$$

(ii) A vector $x_{0} \in K$ is called a weakly efficient solution of (CSTVEP) if

$$
F\left(x_{0}, K\right) \cap(-\operatorname{int} C)=\emptyset .
$$

\section{Second-order composed contingent epiderivatives}

Let $E \subset X$. Let $F: E \rightarrow 2^{Y}$ be a set-valued map, $y_{0} \in F\left(x_{0}\right)$, and $(u, v) \in X \times Y$. We first recall the definition of the generalized second-order composed contingent epiderivative introduced by Li et al. [24].

Definition 3.1 (see [24]) The generalized second-order composed contingent epiderivative $D_{g}^{\prime \prime} F\left(x_{0}, y_{0}, u, v\right)$ of $F$ at $\left(x_{0}, y_{0}\right)$ in the directive $(u, v)$ is the set-valued map from $X$ to $Y$ defined by

$$
D_{g}^{\prime \prime} F\left(x_{0}, y_{0}, u, v\right)(x)=\operatorname{Min}_{C}\left\{y \in Y \mid(x, y) \in T\left(T\left(\operatorname{epi}(F),\left(x_{0}, y_{0}\right)\right),(u, v)\right)\right\} .
$$

Now we introduce the following second-order composed contingent epiderivatives of set-valued maps, and then we investigate some of its properties.

Definition 3.2 Let $\left(x_{0}, y_{0}\right) \in \operatorname{graph}(F),(u, v) \in X \times Y$. The second-order composed contingent epiderivative $D^{\prime \prime} F_{+}\left(x_{0}, y_{0}, u, v\right)$ of $F$ at $\left(x_{0}, y_{0}\right)$ in the directive $(u, v)$ is the set-valued map from $X$ to $Y$ defined by

$$
D^{\prime \prime} F_{+}\left(x_{0}, y_{0}, u, v\right)(x)=\left\{y \in Y \mid(x, y) \in T\left(T\left(\operatorname{epi}(F),\left(x_{0}, y_{0}\right)\right),(u, v)\right)\right\}, \quad \forall x \in X .
$$

Proposition 3.1 Let $(\hat{x}, \hat{y}) \in \operatorname{graph}(F),(\hat{u}, \hat{v}) \in X \times Y$, and $M:=\operatorname{dom} D^{\prime \prime} F_{+}(\hat{x}, \hat{y}, \hat{u}, \hat{v})$. Then

$$
D^{\prime \prime} F_{+}(\hat{x}, \hat{y}, \hat{u}, \hat{v})(x)+C=D^{\prime \prime} F_{+}(\hat{x}, \hat{y}, \hat{u}, \hat{v})(x), \quad \forall x \in M
$$


Proof Let $x \in M, y \in D^{\prime \prime} F_{+}(\hat{x}, \hat{y}, \hat{u}, \hat{v})(x)+C$. Then there exist $(x, \bar{y}) \in T(T($ epi $F,(\hat{x}, \hat{y})),(\hat{u}, \hat{v}))$, and $c \in C$, such that $(x, y)=(x, \bar{y}+c)$. Since $(x, \bar{y}) \in T(T($ epi $F,(\hat{x}, \hat{y})),(\hat{u}, \hat{v}))$, there exist sequences $\left(x_{n}, y_{n}\right) \rightarrow(x, \bar{y})$ and $t_{n} \downarrow 0^{+}$, such that

$$
(\hat{u}, \hat{v})+t_{n}\left(x_{n}, y_{n}\right) \in T(\text { epi } F,(\hat{x}, \hat{y})), \quad \forall n \in N
$$

Moreover, $\forall n \in N$, there exist sequences $\left(x_{n}^{k}, y_{n}^{k}\right) \rightarrow(\hat{u}, \hat{v})+t_{n}\left(x_{n}, y_{n}\right)$ and $t_{n}^{k} \downarrow 0^{+}$, such that $(\hat{x}, \hat{y})+t_{n}^{k}\left(x_{n}^{k}, y_{n}^{k}\right) \in$ epi $F, \forall k \in N$. Then we have

$$
\hat{y}+t_{n}^{k} y_{n}^{k} \in F\left(\hat{x}+t_{n}^{k} x_{n}^{k}\right)+C, \quad \forall n, k \in N .
$$

Since $c \in C$, combine with (2), we have $\hat{y}+t_{n}^{k}\left(y_{n}^{k}+t_{n} c\right)=\hat{y}+t_{n}^{k} y_{n}^{k}+t_{n}^{k} t_{n} c \in F\left(\hat{x}+t_{n}^{k} x_{n}^{k}\right)+$ $C, \forall n, k \in N$. That is $(\hat{x}, \hat{y})+t_{n}^{k}\left(x_{n}^{k}, y_{n}^{k}+t_{n} c\right) \in \operatorname{epi} F_{+}, \forall n, k \in N$. Since $\left(x_{n}^{k}, y_{n}^{k}\right) \rightarrow(\hat{u}, \hat{v})+$ $t_{n}\left(x_{n}, y_{n}\right)$, we have $\left(x_{n}^{k}, y_{n}^{k}+t_{n} c\right) \rightarrow(\hat{u}, \hat{v})+t_{n}\left(x_{n}, y_{n}+c\right)$ as $k \rightarrow+\infty$. Thus,

$$
(\hat{u}, \hat{v})+t_{n}\left(x_{n}, y_{n}+c\right) \in T(\text { epi } F,(\hat{x}, \hat{y})), \quad \forall n \in N
$$

Simultaneously, $\left(x_{n}, y_{n}+c\right) \rightarrow(x, \bar{y}+c)$, since $\left(x_{n}, y_{n}\right) \rightarrow(x, \bar{y})$ as $n \rightarrow+\infty$. Together with $(x, y)=(\bar{x}, \bar{y}+c)$, we have $(x, y)=T(T($ epi $F,(\hat{x}, \hat{y})),(\hat{u}, \hat{v}))$, which implies

$$
y \in D^{\prime \prime} F_{+}(\hat{x}, \hat{y}, \hat{u}, \hat{v})(x)
$$

So

$$
D^{\prime \prime} F_{+}(\hat{x}, \hat{y}, \hat{u}, \hat{v})(x)+C \subseteq D^{\prime \prime} F_{+}(\hat{x}, \hat{y}, \hat{u}, \hat{v})(x)
$$

Naturally, $D^{\prime \prime} F_{+}(\hat{x}, \hat{y}, \hat{u}, \hat{v})(x) \subseteq D^{\prime \prime} F_{+}(\hat{x}, \hat{y}, \hat{u}, \hat{v})(x)+C$. Thus (1) holds, and this completes the proof.

By definitions and Proposition 3.1, we can conclude that the following result holds.

Proposition 3.2 Let $F: E \rightarrow 2^{Y},\left(x_{0}, y_{0}\right) \in \operatorname{graph}(F),(u, v) \in T\left(\operatorname{epi}(F),\left(x_{0}, y_{0}\right)\right)$, and $x \in X$. Then $D_{g}^{\prime \prime} F\left(x_{0}, y_{0}, u, v\right)(x)+C \subseteq D^{\prime \prime} F_{+}\left(x_{0}, y_{0}, u, v\right)(x)$.

Remark 3.1 The inclusion relation

$$
D^{\prime \prime} F_{+}\left(x_{0}, y_{0}, u, v\right)(x) \subseteq D_{g}^{\prime \prime} F\left(x_{0}, y_{0}, u, v\right)(x)+C
$$

may not hold.

Now we give the following example to explain Remark 3.1.

Example 3.1 Let $C=R_{+}^{2}$ and $F(x)=\left\{\left(y_{1}, y_{2}\right) \in R^{2} \mid y_{1} \geq x^{2}, y_{2} \in R\right\}, \forall x \in R_{+}$. Let $\left(x_{0}, y_{0}\right)=$ $(0,(0,0))$, and $(u, v)=(1,(0,1))$. Then

$$
T\left(T\left(\operatorname{epi}(F),\left(x_{0}, y_{0}\right)\right),(u, v)\right)=\left\{\left(x,\left(y_{1}, y_{2}\right)\right) \in R \times R^{2} \mid x \in R, y_{1} \geq 0, y_{2} \in R\right\} \text {. }
$$


Therefore, for any $x \in R$, we have

$$
D_{g}^{\prime \prime} F\left(x_{0}, y_{0}, u, v\right)(x)=\emptyset
$$

and

$$
D^{\prime \prime} F_{+}\left(x_{0}, y_{0}, u, v\right)(x)=\left\{\left(y_{1}, y_{2}\right) \mid y_{1} \geq 0, y_{2} \in R\right\}
$$

And then, for any $x \in R$, we have

$$
D^{\prime \prime} F_{+}\left(x_{0}, y_{0}, u, v\right)(x) \nsubseteq D_{g}^{\prime \prime} F\left(x_{0}, y_{0}, u, v\right)(x)+C .
$$

Now we discuss some crucial properties of the second-order composed contingent epiderivative.

Proposition 3.3 Let $\left(x_{0}, y_{0}\right) \in \operatorname{graph} F,(u, v) \in T\left(\right.$ epi $\left.F,\left(x_{0}, y_{0}\right)\right)$ with $v \in C$ and $E \subset X$ be convex. If $F$ is $C$-convex on $E$, then for all $x \in E$,

$$
F(x)-\left\{y_{0}\right\}+C \subset D^{\prime \prime} F_{+}\left(x_{0}, y_{0}, u, v\right)\left(x-x_{0}-u\right) .
$$

Proof Since $F$ is $C$-convex on $E$, epi $F$ is a convex set. So it follows from Proposition 2.3 that

$$
T\left(T\left(\text { epi } F,\left(x_{0}, y_{0}\right)\right),(u, v)\right)=\operatorname{clcone}\left(\operatorname{cone}\left(\text { epi } F-\left\{\left(x_{0}, y_{0}\right)\right\}\right)-\{(u, v)\}\right) .
$$

Since for every $c \in C, x \in S$ and $y \in F(x)$, one has

$$
\begin{aligned}
& \left(x-x_{0}-u, y-y_{0}+c\right) \\
& \quad=\left(x-x_{0}-u, y+c+v-y_{0}-v\right) \in\{x\} \times(F(x)+C)-\left\{\left(x_{0}, y_{0}\right)\right\}-\{(u, v)\} .
\end{aligned}
$$

Then it follows from (3) that

$$
\left(x-x_{0}-u, y-y_{0}\right) \in T\left(T\left(\text { epi } F,\left(x_{0}, y_{0}\right)\right),(u, v)\right) \text {. }
$$

Thus, by the definition of the second-order composed contingent epiderivative, we have

$$
y-y_{0}+c \in D^{\prime \prime} F_{+}\left(x_{0}, y_{0}, u, v\right)\left(x-x_{0}-u\right),
$$

and then

$$
F(x)-\left\{y_{0}\right\}+C \subset D^{\prime \prime} F_{+}\left(x_{0}, y_{0}, u, v\right)\left(x-x_{0}-u\right), \quad \forall x \in E .
$$

The proof is complete. 
Proposition 3.4 Let $\left(x_{0}, y_{0}\right) \in \operatorname{graph}(F),(u, v) \in T$ (epi $\left.F,\left(x_{0}, y_{0}\right)\right)$. Then

(i) $D^{\prime \prime} F_{+}\left(x_{0}, y_{0}, u, v\right)$ is strictly positive homogeneous.

Moreover, if $F$ is $C$-convex on a nonempty convex set $E$, then

(ii) $D^{\prime \prime} F_{+}\left(x_{0}, y_{0}, u, v\right)$ is subadditive.

Proof (i) Let $\alpha>0$ and $x \in X$.

If $y \in D^{\prime \prime} F_{+}\left(x_{0}, y_{0}, u, v\right)(x)$, then there exist sequences $\left\{h_{n}\right\}$ with $h_{n} \rightarrow 0^{+}$and $\left\{\left(x_{n}, y_{n}\right)\right\}$ with $\left(x_{n}, y_{n}\right) \in T\left(\right.$ epi $\left.F,\left(x_{0}, y_{0}\right)\right)$ such that

$$
\frac{\left(x_{n}, y_{n}\right)-(u, v)}{h_{n}} \rightarrow(x, y),
$$

and then

$$
\frac{\left(x_{n}, y_{n}\right)-(u, v)}{\frac{1}{\alpha} h_{n}} \rightarrow(\alpha x, \alpha y) .
$$

So $(\alpha x, \alpha y) \in T\left(T\left(\right.\right.$ epi $\left.\left.F,\left(x_{0}, y_{0}\right)\right), u, v\right)$, and then we can obtain

$$
\alpha y \in D^{\prime \prime} F_{+}\left(x_{0}, y_{0}, u, v\right)(\alpha x) \text {. }
$$

Thus

$$
\alpha D^{\prime \prime} F_{+}\left(x_{0}, y_{0}, u, v\right)(x) \subseteq D^{\prime \prime} F_{+}\left(x_{0}, y_{0}, u, v\right)(x)(\alpha x)
$$

The proof of

$$
D^{\prime \prime} F_{+}\left(x_{0}, y_{0}, u, v\right)(\alpha x) \subseteq \alpha D^{\prime \prime} F_{+}\left(x_{0}, y_{0}, u, v\right)(x)(x)
$$

follows along the lines of (4). So $D^{\prime \prime} F_{+}\left(x_{0}, y_{0}, u, v\right)$ is strictly positive homogeneous.

(ii) Let $x_{1}, x_{2} \in X, y_{1} \in D^{\prime \prime} F_{+}\left(x_{0}, y_{0}, u, v\right)\left(x_{1}\right), y_{2} \in D^{\prime \prime} F_{+}\left(x_{0}, y_{0}, u, v\right)\left(x_{2}\right)$. Then one has

$$
\left(x_{1}, y_{1}\right) \in T\left(T\left(\text { epi } F,\left(x_{0}, y_{0}\right)\right),(u, v)\right), \quad\left(x_{2}, y_{2}\right) \in T\left(T\left(\text { epi } F,\left(x_{0}, y_{0}\right)\right),(u, v)\right) .
$$

Since $F$ is $C$-convex on $S$, epi $F$ is convex, and then $T\left(T\left(\right.\right.$ epi $\left.\left.F,\left(x_{0}, y_{0}\right)\right),(u, v)\right)$ is a close and convex cone. Thus we have

$$
\left(x_{1}+x_{2}, y_{1}+y_{2}\right) \in T\left(T\left(\text { epi } F,\left(x_{0}, y_{0}\right)\right),(u, v)\right) \text {, }
$$

and then

$$
y_{1}+y_{2} \in D^{\prime \prime} F_{+}\left(x_{0}, y_{0}, u, v\right)\left(x_{1}+x_{2}\right) \text {. }
$$

Thus

$$
D^{\prime \prime} F_{+}\left(x_{0}, y_{0}, u, v\right)\left(x_{1}\right)+D^{\prime \prime} F_{+}\left(x_{0}, y_{0}, u, v\right)\left(x_{2}\right) \subset D^{\prime \prime} F_{+}\left(x_{0}, y_{0}, u, v\right)\left(x_{1}+x_{2}\right)+C,
$$

and the proof is complete.

By the proof of Proposition 3.4, we can conclude that the following result holds. 
Proposition 3.5 Let $\left(x_{0}, y_{0}\right) \in \operatorname{graph}(F),(u, v) \in T\left(\operatorname{epi} F,\left(x_{0}, y_{0}\right)\right), M:=\operatorname{dom} D^{\prime \prime} F_{+}\left(x_{0}\right.$, $\left.y_{0}, u, v\right)$. If $F$ is $C$-convex on a nonempty convex set $E$, then $D^{\prime \prime} F_{+}\left(x_{0}, y_{0}, u, v\right)(M)$ is a convex cone.

\section{Second-order optimality conditions of weakly efficient solutions}

Throughout this section, let $x_{0} \in K, y_{0}=0_{Y} \in F_{x_{0}}\left(x_{0}\right)$, int $C \neq \emptyset$, and int $D \neq \emptyset$. Firstly, we recall a definition and a result in [25].

Let $K \subset X$ and $x_{0} \in K$. The interior tangent cone of $K$ at $x_{0}$ defined as

$$
I T\left(K, x_{0}\right)=\left\{u \in X \mid \exists \delta>0 \text { such that } x_{0}+t u^{\prime} \in K, \forall t \in(0, \delta], \forall u^{\prime} \in B_{X}(u, \delta)\right\},
$$

where $B_{X}(u, \delta)$ stands for the closed ball centered at $u \in X$ and of radius $\delta$.

Lemma 4.1 (see [25]) If $K \subset X$ is convex, $x_{0} \in K$, and $\operatorname{int} K \neq \emptyset$, then

$$
I T\left(\operatorname{int} K, x_{0}\right)=\operatorname{intcone}\left(K-x_{0}\right) .
$$

Theorem 4.1 Let $x_{0}$ be a weakly efficient solution of the problem (USVVEP). Then, for every $(u, v) \in T\left(\operatorname{epi} F_{x_{0}},\left(x_{0}, y_{0}\right)\right)$ with $v \in-\partial C$, we have

$$
\left[D^{\prime \prime}\left(F_{x_{0}}\right)_{+}\left(x_{0}, y_{0}, u, v\right)(x)+\operatorname{line}\{v\}\right] \cap(-\operatorname{int} C)=\emptyset,
$$

for every $x \in \operatorname{dom} D^{\prime \prime}\left(F_{x_{0}}\right)_{+}\left(x_{0}, y_{0}, u, v\right)$.

Proof Suppose to the contrary that there exists an $x \in \operatorname{dom} D^{\prime \prime}\left(F_{x_{0}}\right)_{+}\left(x_{0}, y_{0}, u, v\right)$ such that (5) does not hold. Then there exist $\lambda \in R$ and

$$
y \in D^{\prime \prime}\left(F_{x_{0}}\right)_{+}\left(x_{0}, y_{0}, u, v\right)(x)
$$

such that

$$
y^{\prime}:=y+\lambda v \in-\operatorname{int} C
$$

Let us consider two possible cases for $\lambda$.

Case 1: If $\lambda>0$, then it follows from Proposition 3.1 and (6) that $y^{\prime} \in D^{\prime \prime}\left(F_{x_{0}}\right)_{+}\left(x_{0}, y_{0}\right.$, $u, v)(x)$. So

$$
\left(x, y^{\prime}\right) \in T\left(T\left(\operatorname{epi} F_{x_{0}},\left(x_{0}, y_{0}\right)\right),(u, v)\right) .
$$

By definition, there exist sequences $\lambda_{n} \rightarrow+\infty$ and $\left(u_{n}, v_{n}\right) \in T\left(\operatorname{epi} F,\left(x_{0}, y_{0}\right)\right)$ such that $\left(u_{n}, v_{n}\right) \rightarrow(u, v)$ and

$$
\lambda_{n}\left(\left(u_{n}, v_{n}\right)-(u, v)\right) \rightarrow\left(x, y^{\prime}\right), \quad \text { as } n \rightarrow+\infty .
$$

It follows from (9), (7), and $v \in-C$ that there exists $N_{1} \in \mathcal{N}$ such that

$$
v_{n} \in-\operatorname{int} C, \quad \forall n>N_{1} .
$$


Since $\left(u_{n}, v_{n}\right) \in T$ (epi $\left.F_{x_{0}},\left(x_{0}, y_{0}\right)\right)$, for every $n \in \mathcal{N}$, there exist a sequence $\lambda_{n}^{k} \rightarrow+\infty$ as $k \rightarrow+\infty$ and a sequence $\left(x_{n}^{k}, y_{n}^{k}\right) \in$ epi $F$, such that $\left(x_{n}^{k}, y_{n}^{k}\right) \rightarrow\left(x_{0}, y_{0}\right)$ and

$$
\lambda_{n}^{k}\left(\left(x_{n}^{k}, y_{n}^{k}\right)-\left(x_{0}, y_{0}\right)\right) \rightarrow\left(u_{n}, v_{n}\right), \quad \text { as } k \rightarrow+\infty .
$$

It follows from (10) that there exists $N_{1}(n) \in \mathcal{N}$ such that

$$
\lambda_{n}^{k}\left(y_{n}^{k}-y_{0}\right) \in-\operatorname{int} C, \quad \forall k>N_{1}(n), \forall n>N_{1},
$$

which implies

$$
y_{n}^{k}-y_{0} \in-\operatorname{int} C, \quad \forall k>N_{1}(n), \forall n>N_{1} .
$$

Since $\left(x_{n}^{k}, y_{n}^{k}\right) \in \operatorname{epi} F_{x_{0}}$, there exists $\bar{y}_{n}^{k} \in F_{x_{0}}\left(x_{n}^{k}\right)$ such that $y_{n}^{k} \in\left\{\bar{y}_{n}^{k}\right\}+C$. Then, by (12), we have

$$
\bar{y}_{n}^{k}-y_{0} \in-\operatorname{int} C, \quad \forall k>N_{1}(n), \forall n>N_{1} .
$$

Therefore

$$
F\left(x_{0}, x_{n}^{k}\right) \cap(-\operatorname{int} C) \neq \emptyset,
$$

which contradicts that $\left(x_{0}, y_{0}\right)$ is a weakly efficient solution of the problem (USVVEP).

Case 2: If $\lambda \leq 0$, then it follows from Proposition $v \in-C$ and (7) that $y \in-\operatorname{int} C$ and

$$
(x, y) \in T\left(T\left(\text { epi } F_{x_{0}},\left(x_{0}, y_{0}\right)\right),(u, v)\right) .
$$

By a similar proof method to case 1 , there exist consequences $\bar{x}_{n}^{k}$ and $N_{2}, N_{2}(n) \in \mathcal{N}$ such that

$$
F\left(x_{0}, \bar{x}_{n}^{k}\right) \cap(-\operatorname{int} C) \neq \emptyset, \quad \forall k>N_{2}(n), \forall n>N_{2},
$$

which contradicts that $x_{0}$ is a weakly efficient solution of the problem (USVVEP). Thus (5) holds, and the proof is complete.

Remark 4.1 In Theorem 4.1, we cannot use $v \in-\operatorname{int} C$ instead of $v \in-\partial C$. Since $\left(x_{0}, y_{0}\right)$ is a weakly efficient solution of the problem (USVVEP),

$$
F_{x_{0}}(x) \cap(-\operatorname{int} C)=\emptyset, \quad \forall x \in E .
$$

It follows from $(u, v) \in T\left(\operatorname{epi}\left(F_{x_{0}}\right),\left(x_{0}, y_{0}\right)\right)$, and $y_{0}=0$ that there exist sequences $\left\{\lambda_{n}\right\}$ with $\lambda_{n} \rightarrow+\infty$ and $\left(x_{n}, y_{n}\right) \in \operatorname{epi}\left(F_{x_{0}}\right)$ with $\left(x_{n}, y_{n}\right) \rightarrow\left(x_{0}, 0\right)$ such that

$$
\lambda_{n}\left(\left(x_{n}, y_{n}\right)-\left(x_{0}, 0\right)\right) \rightarrow(u, v), \quad \text { as } n \rightarrow+\infty .
$$

So, it follows from $v \in-\operatorname{int} C$ that there exists $N \in \mathcal{N}$ such that

$$
\lambda_{n} y_{n} \in-\operatorname{int} C, \quad \forall n>N,
$$


which implies

$$
y_{n} \in-\operatorname{int} C, \quad \forall n>N .
$$

Since $\left(x_{n}, y_{n}\right) \in \operatorname{epi}\left(F_{x_{0}}\right)$, there exists $\bar{y}_{n} \in F_{x_{0}}\left(x_{n}\right)$ such that $y_{n} \in\left\{\bar{y}_{n}\right\}+C$. Then, combined with (14), we have

$$
\bar{y}_{n} \in-\operatorname{int} C, \quad \forall n>N .
$$

Therefore

$$
F_{x_{0}}\left(x_{n}\right) \cap(-\operatorname{int} C) \neq \emptyset, \quad \forall x_{n} \in E, \forall n>\max \left\{N, N_{1}\right\},
$$

which contradicts (13).

Next, we give an example to illustrate Theorem 4.1.

Example 4.1 Let $F(x)=\left\{\left(y_{1}, y_{2}\right) \in R^{2} \mid y_{1} \in R, y_{2} \geq x^{2}\right\}, \forall x \in R_{+},\left(x_{0}, y_{0}\right)=(0,(0,0))$, and $C=R_{+}^{2}$. Then $T\left(\operatorname{epi}(F),\left(x_{0}, y_{0}\right)\right)=\left\{\left(u,\left(v_{1}, v_{2}\right)\right) \in R \times R^{2} \mid x \in R_{+}, v_{1} \in R, v_{2} \geq 0\right\}$. Take $(u, v)=$ $(1,(-1,0))$. Then

$$
T\left(T\left(\operatorname{epi}(F),\left(x_{0}, y_{0}\right)\right),(u, v)\right)=\left\{\left(x,\left(y_{1}, y_{2}\right)\right) \in R \times R^{2} \mid x \in R, y_{1} \in R, y_{2} \geq 0\right\} .
$$

Therefore, for any $x \in R$, we have

$$
D^{\prime \prime} F_{+}\left(x_{0}, y_{0}, u, v\right)(x)+\operatorname{line}\{v\}=\left\{\left(y_{1}, y_{2}\right) \mid y_{1} \in R, y_{2} \geq 0\right\} \text {. }
$$

And then, for any $x \in R$, we have

$$
\left[D^{\prime \prime} F_{+}\left(x_{0}, y_{0}, u, v\right)(x)+\operatorname{line}\{v\}\right] \cap(-\operatorname{int} C)=\emptyset,
$$

which shows that Theorem 4.1 holds.

Theorem 4.2 Let $(u, v) \in T\left(\right.$ epi $\left.F_{x_{0}}\left(x_{0}, y_{0}\right)\right)$ with $v \in C$ and $E \subset X$ be convex. If $F_{x_{0}}$ is $C$ convex on $E$, and for all $x \in E$,

$$
D^{\prime \prime}\left(F_{x_{0}}\right)_{+}\left(x_{0}, y_{0}, u, v\right)\left(x-x_{0}-u\right) \cap(-\operatorname{int} C)=\emptyset,
$$

then $x_{0}$ is a weakly efficient solution of the problem (USVVEP).

Proof It follows from Proposition 3.3 that

$$
\left(F_{x_{0}}\right)(x) \subset D^{\prime \prime}\left(F_{x_{0}}\right)_{+}\left(x_{0}, y_{0}, u, v\right)\left(x-x_{0}-u\right), \quad \forall x \in E .
$$

Then, from (15), we have

$$
\left(F_{x_{0}}\right)(x) \cap(-\operatorname{int} C)=\emptyset, \quad \forall x \in E .
$$

So $x_{0}$ is a weakly efficient solution of (USVVEP), and the proof is complete. 
Theorem 4.3 Let $(u, v, w) \in T\left(\operatorname{epi}\left(F_{x_{0}}, G\right), x_{0}, y_{0}, z_{0}\right)$ with $v \in-\partial C$ and $w \in-D$. If $x_{0}$ is a weakly efficient solution of $(C S V V E P)$, then for any $z_{0} \in G\left(x_{0}\right) \cap(-D)$,

$$
\begin{aligned}
& D^{\prime \prime}\left(F_{x_{0}}, G\right)_{+}\left(x_{0}, y_{0}, z_{0}, u, v, w+z_{0}\right)(x) \\
& \quad \cap-\operatorname{cone}\left(\operatorname{int}(C \times D)+\operatorname{line}\left\{\left(v, w+z_{0}\right)\right\}\right) \backslash\left\{\left(0_{Y}, 0_{Z}\right)\right\}=\emptyset,
\end{aligned}
$$

for all $x \in \Omega:=\operatorname{dom}\left[D^{\prime \prime}\left(F_{x_{0}}, G\right)_{+}\left(x_{0}, y_{0}, z_{0}, u, v, w+z_{0}\right)\right]$.

Proof To prove the result by contradiction, suppose that there exists an $x \in \Omega$ such that (16) does not hold, that is, there exists a $(y, z) \in Y \times Z$ such that

$$
(y, z) \in D^{\prime \prime}\left(F_{x_{0}}, G\right)_{+}\left(x_{0}, y_{0}, z_{0}, u, v, w+z_{0}\right)(x)
$$

and

$$
(y, z) \in-\operatorname{cone}\left(\operatorname{int}(C \times D)+\operatorname{line}\left\{\left(v, w+z_{0}\right)\right\}\right) \backslash\left\{\left(0_{Y}, 0_{Z}\right)\right\} .
$$

Then, by the definition of second-order composed contingent epiderivatives, there exist sequences $\lambda_{n} \rightarrow+\infty$ and $\left(u_{n}, v_{n}, w_{n}\right) \in T\left(\operatorname{epi}\left(F_{x_{0}}, G\right),\left(x_{0}, y_{0}, z_{0}\right)\right)$ such that $\left(u_{n}, v_{n}, w_{n}\right) \rightarrow$ $\left(u, v, w+z_{0}\right)$ and

$$
\lambda_{n}\left(\left(u_{n}, v_{n}, w_{n}\right)-\left(u, v, w+z_{0}\right)\right) \rightarrow(x, y, z), \quad \text { as } n \rightarrow+\infty .
$$

It follows from (17) that there exist $\mu>0, v \in R, c \in \operatorname{int} C$, and $d \in \operatorname{int} D$ such that

$$
y=-\mu(c+v v), \quad z=-\mu\left(d+v\left(w+z_{0}\right)\right) .
$$

Let us consider two possible cases for $v$.

Case 1: If $v \leq 0$, then, from (19), $v \in-C$, and $w, z_{0} \in-D$, we have $y \in-\operatorname{int} C$ and $z \in$ $-\operatorname{int} D$. Thus, by (18), there exists $N_{1} \in \mathcal{N}$ such that

$$
\lambda_{n}\left(v_{n}-v\right) \in-\operatorname{int} C, \quad \lambda_{n}\left(w_{n}-\left(w+z_{0}\right)\right) \in-\operatorname{int} D, \quad \forall n>N_{1} .
$$

Thus, it follows from $v \in-C$ and $w \in-D$ that

$$
v_{n} \in-\operatorname{int} C, \quad w_{n} \in-\operatorname{int} D, \quad \forall n>N_{1} .
$$

Since $\left(u_{n}, v_{n}, w_{n}\right) \in T\left(\operatorname{epi}\left(F_{x_{0}}, G\right),\left(x_{0}, y_{0}, z_{0}\right)\right)$, for every $n \in \mathcal{N}$, there exist a sequence $\left\{\lambda_{n}^{k}\right\}$ with $\lambda_{n}^{k} \rightarrow+\infty$ as $k \rightarrow+\infty$ and a sequence $\left(x_{n}^{k}, y_{n}^{k}, z_{n}^{k}\right) \in \operatorname{epi}\left(F_{x_{0}}, G\right)$, such that $\left(x_{n}^{k}, y_{n}^{k}, z_{n}^{k}\right) \rightarrow$ $\left(x_{0}, y_{0}, z_{0}\right)$ and

$$
\lambda_{n}^{k}\left(\left(x_{n}^{k}, y_{n}^{k}, z_{n}^{k}\right)-\left(x_{0}, y_{0}, z_{0}\right)\right) \rightarrow\left(u_{n}, v_{n}, w_{n}\right), \quad \text { as } k \rightarrow+\infty .
$$

It follows from (20) and (21) that there exists $N_{1}(n) \in \mathcal{N}$ such that

$$
\lambda_{n}^{k}\left(y_{n}^{k}-y_{0}\right) \in-\operatorname{int} C, \quad \lambda_{n}^{k}\left(z_{n}^{k}-z_{0}\right) \in-\operatorname{int} D, \quad \forall k>N_{1}(n), \forall n>N_{1},
$$


which implies

$$
y_{n}^{k}-y_{0} \in-\operatorname{int} C, \quad z_{n}^{k}-z_{0} \in-\operatorname{int} D, \quad \forall k>N_{1}(n), \forall n>N_{1} .
$$

Since $\left(x_{n}^{k}, y_{n}^{k}, z_{n}^{k}\right) \in \operatorname{epi}\left(F_{x_{0}}, G\right)$, there exist $\bar{y}_{n}^{k} \in F_{x_{0}}\left(x_{n}^{k}\right), \bar{z}_{n}^{k} \in G\left(x_{n}^{k}\right), c \in C$ and $d \in D$ such that $y_{n}^{k}=\bar{y}_{n}^{k}+c$ and $z_{n}^{k}=\bar{z}_{n}^{k}+d$. Then, by (22) and $y_{0}=0$, we have

$$
\bar{y}_{n}^{k} \in-\operatorname{int} C, \quad \forall k>N_{1}(n), \quad \bar{z}_{n}^{k} \in-\operatorname{int} D, \quad \forall n>N_{1} .
$$

So

$$
F_{x_{0}}\left(x_{n}^{k}\right) \cap-\operatorname{int} C \neq \emptyset, \quad x_{n}^{k} \in K, \forall k>N_{1}(n), \forall n>N_{1},
$$

which contradicts that $x_{0}$ is a weakly efficient solution of (CSVVEP).

Case 2: If $v>0$, then, from (19), we get $y=-\mu v\left(\frac{1}{v} c+v\right)$ and $z=-\mu v\left(\frac{1}{v} d+\left(w+z_{0}\right)\right)$. So it follows from $c \in \operatorname{int} C$ and $d \in \operatorname{int} D$ that

$$
y \in-\text { intcone }(C+\{v\}), \quad z=-\operatorname{intcone}\left(D+\left\{w+z_{0}\right\}\right) .
$$

Then, by Lemma 4.1 and (23), we get $y \in I T(-\operatorname{int} C, v)$ and $z=I T\left(-\operatorname{int} D, w+z_{0}\right)$. Therefore, there exists $\delta>0$ such that

$$
\begin{aligned}
& v+\delta y^{\prime} \in-\operatorname{int} C, \quad \forall y^{\prime} \in B_{Y}(y, \delta), \\
& w+z_{0}+\delta z^{\prime} \in-\operatorname{int} D, \quad \forall y^{\prime} \in B_{Z}(z, \delta) .
\end{aligned}
$$

For this $\delta$, it follows from (18) that there exists $N_{2} \in \mathcal{N}$ such that

$$
\delta \lambda_{n}>1, \quad \lambda_{n}\left(v_{n}-v\right) \in B_{Y}(y, \delta), \quad \lambda_{n}\left(w_{n}-\left(w+z_{0}\right)\right) \in B_{Z}(z, \delta), \quad \forall n>N_{2} .
$$

Then, by (24) and (25), we have

$$
v_{n}-\left(1-\frac{1}{\delta \lambda_{n}}\right) v \in-\operatorname{int} C, \quad w_{n}-\left(1-\frac{1}{\delta \lambda_{n}}\right)\left(w+z_{0}\right) \in-\operatorname{int} D, \quad \forall n>N_{2} .
$$

Thus, from $v \in-C, w, z_{0} \in-D$, and $\delta \lambda_{n}>1, \forall n>N_{2}$, we have

$$
v_{n} \in-\operatorname{int} C, \quad w_{n} \in-\operatorname{int} D, \quad \forall n>N_{2} .
$$

By a similar proof method to case 1 , there exists $N_{2}(n) \in \mathcal{N}$ such that

$$
F_{x_{0}}\left(x_{n}^{k}\right) \cap-\operatorname{int} C \neq \emptyset, \quad x_{n}^{k} \in K, \forall k>N_{2}(n), \forall n>N_{2},
$$

which contradicts that $x_{0}$ is a weakly efficient solution of (CSVVEP). Thus (16) holds and the proof is complete. 
Theorem 4.4 Let $(u, v, w) \in T\left(\operatorname{epi}\left(F_{x_{0}}, G\right), x_{0}, y_{0}, z_{0}\right)$ with $v \in-\partial C$ and $w \in-D$. If $x_{0}$ is a weakly efficient solution of $(C S V V E P)$, then for any $z_{0} \in G\left(x_{0}\right) \cap(-D)$,

$$
D^{\prime \prime}\left(F_{x_{0}}, G\right)_{+}\left(x_{0}, y_{0}, z_{0}, u, v, w+z_{0}\right)(x) \cap-\left(\operatorname{int}(C \times D)+\left\{\left(0, z_{0}\right)\right\}\right)=\emptyset
$$

for all $x \in \Omega:=\operatorname{dom}\left[D^{\prime \prime}\left(F_{x_{0}}, G\right)_{+}\left(x_{0}, y_{0}, z_{0}, u, v, w+z_{0}\right)\right]$.

Proof To prove the result by contradiction, suppose that there exists an $x \in \Omega$ such that (26) does not hold, that is, there exists $(y, z) \in Y \times Z$ such that

$$
\begin{aligned}
& (y, z) \in D^{\prime \prime}\left(F_{x_{0}}, G\right)_{+}\left(x_{0}, y_{0}, z_{0}, u, v, w+z_{0}\right)(x), \\
& (y, z) \in-\left(\operatorname{int}(C \times D)+\left\{\left(0, z_{0}\right)\right\}\right) .
\end{aligned}
$$

Then, by the definition of second-order composed contingent epiderivatives, there exist sequences $\lambda_{n} \rightarrow+\infty$ and $\left(u_{n}, v_{n}, w_{n}\right) \in T\left(\operatorname{epi}\left(F_{x_{0}}, G\right),\left(x_{0}, y_{0}, z_{0}\right)\right)$ such that $\left(u_{n}, v_{n}, w_{n}\right) \rightarrow$ $\left(u, v, w+z_{0}\right)$ and

$$
\lambda_{n}\left(\left(u_{n}, v_{n}, w_{n}\right)-\left(u, v, w+z_{0}\right)\right) \rightarrow(x, y, z), \quad \text { as } n \rightarrow+\infty .
$$

It follows from (27) that there exist $c \in \operatorname{int} C$ and $d \in \operatorname{int} D$ such that

$$
y=-c, \quad z=-\left(d+z_{0}\right) .
$$

Thus, by (28), there exists $N_{1} \in \mathcal{N}$ such that

$$
\lambda_{n}>1, \quad \lambda_{n}\left(v_{n}-v\right) \in-\operatorname{int} C, \quad \lambda_{n}\left(w_{n}-\left(w+z_{0}\right)\right) \in-\left(\operatorname{int} D+z_{0}\right), \quad \forall n>N_{1} .
$$

Thus, it follows from $v \in-C$ and $w, z_{0} \in-D$ that

$$
v_{n} \in-\operatorname{int} C, \quad w_{n} \in-\operatorname{int} D, \quad \forall n>N_{1} .
$$

Since $\left(u_{n}, v_{n}, w_{n}\right) \in T\left(\operatorname{epi}\left(F_{x_{0}}, G\right),\left(x_{0}, y_{0}, z_{0}\right)\right)$, for every $n \in \mathcal{N}$, there exist a sequence $\left\{\lambda_{n}^{k}\right\}$ with $\lambda_{n}^{k} \rightarrow+\infty$ as $k \rightarrow+\infty$ and a sequence $\left(x_{n}^{k}, y_{n}^{k}, z_{n}^{k}\right) \in \operatorname{epi}\left(F_{x_{0}}, G\right)$, such that $\left(x_{n}^{k}, y_{n}^{k}, z_{n}^{k}\right) \rightarrow$ $\left(x_{0}, y_{0}, z_{0}\right)$ and

$$
\lambda_{n}^{k}\left(\left(x_{n}^{k}, y_{n}^{k}, z_{n}^{k}\right)-\left(x_{0}, y_{0}, z_{0}\right)\right) \rightarrow\left(u_{n}, v_{n}, w_{n}\right), \quad \text { as } k \rightarrow+\infty .
$$

It follows from (30) and (31) that there exists $N_{1}(n) \in \mathcal{N}$ such that

$$
\lambda_{n}^{k}\left(y_{n}^{k}-y_{0}\right) \in-\operatorname{int} C, \quad \lambda_{n}^{k}\left(z_{n}^{k}-z_{0}\right) \in-\operatorname{int} D, \quad \forall k>N_{1}(n), \forall n>N_{1},
$$

which implies

$$
y_{n}^{k}-y_{0} \in-\operatorname{int} C, \quad z_{n}^{k}-z_{0} \in-\operatorname{int} D, \quad \forall k>N_{1}(n), \forall n>N_{1} .
$$


Since $\left(x_{n}^{k}, y_{n}^{k}, z_{n}^{k}\right) \in \operatorname{epi}\left(F_{x_{0}}, G\right)$, there exist $\bar{y}_{n}^{k} \in F_{x_{0}}\left(x_{n}^{k}\right), \bar{z}_{n}^{k} \in G\left(x_{n}^{k}\right), c \in C$, and $d \in D$ such that $y_{n}^{k}=\bar{y}_{n}^{k}+c$ and $z_{n}^{k}=\bar{z}_{n}^{k}+d$. Then, by (32) and $y_{0}=0$, we have

$$
\bar{y}_{n}^{k} \in-\operatorname{int} C, \quad \forall k>N_{1}(n), \quad \bar{z}_{n}^{k} \in-\operatorname{int} D, \quad \forall n>N_{1} .
$$

So

$$
F_{x_{0}}\left(x_{n}^{k}\right) \cap-\operatorname{int} C \neq \emptyset, \quad x_{n}^{k} \in K, \forall k>N_{1}(n), \forall n>N_{1},
$$

which contradicts that $x_{0}$ is a weakly efficient solution of (CSVVEP). Thus (26) holds and the proof is complete.

Theorem 4.5 Let $E \subset X$ be a nonempty convex set, $z_{0} \in G\left(x_{0}\right) \cap(-D)$ and $(u, v, w) \in X \times$ $(-C) \times(-D)$. Suppose that the following conditions are satisfied:

(i) $\left(F_{x_{0}}, G\right)$ is $C \times D$-convex on $E$.

(ii) $x_{0}$ is a weakly efficient solution of (CSVVEP).

Then there exist $\phi \in C^{*}$ and $\psi \in D^{*}$, not both zero functionals, such that

$$
\inf \left\{\bigcup_{(y, z) \in A} \phi(y)+\psi(z)\right\}=0 \text { and } \psi\left(z_{0}\right)=0
$$

where $A:=\bigcup_{x \in \Omega} D^{\prime \prime}\left(F_{x_{0}}, G\right)_{+}\left(x_{0}, y_{0}, z_{0}, u, v, w+z_{0}\right)(x)$ and $\Omega:=\operatorname{dom}\left[D^{\prime \prime}\left(F_{x_{0}}, G\right)_{+}\left(x_{0}, y_{0}, z_{0}\right.\right.$, $\left.\left.u, v, w+z_{0}\right)\right]$.

Proof Define $M=A+\left(0_{Y}, z_{0}\right)$. By Proposition 3.5, we see that $M$ is a convex set. By Theorem 4.4, we get

$$
M \cap(-\operatorname{int}(C \times D))=\emptyset .
$$

By the separation theorem of convex sets, there exist $\phi \in Y^{*}$ and $\psi \in Z^{*}$, not both zero functionals, such that

$$
\phi(y)+\psi(z) \geq \phi(\bar{y})+\psi(\bar{z}), \quad \text { for all }(y, z) \in M,(\bar{y}, \bar{z}) \in-\operatorname{int}(C \times D) .
$$

Since int $C \cup\left\{0_{Y}\right\}$ and int $D \cup\left\{0_{Z}\right\}$ are cones, by (33), we have

$$
\phi(\bar{y}) \leq \psi(\bar{z}), \quad \text { for all }(\bar{y}, \bar{z}) \in-\operatorname{int} C \times \operatorname{int} D,
$$

and

$$
\phi(y)+\psi(z) \geq 0, \quad \text { for all }(y, z) \in M .
$$

From (34), we find that $\psi$ is bounded below on $\operatorname{int} D$. Then $\psi(z) \geq 0$, for all $z \in \operatorname{int} D$. Naturally $\psi \in D^{*}$.

By a similar line of proof to $\psi \in D^{*}$, we can obtain $\phi \in C^{*}$. 
It follows from Proposition 3.5 that $\left(0_{Y}, 0_{Z}\right) \in A$, and then, from $z_{0} \in-D, \psi \in D^{*}$, and (35), we obtain

$$
\inf \left\{\bigcup_{(y, z) \in A} \phi(y)+\psi(z)\right\}=0 \text { and } \psi\left(z_{0}\right)=0
$$

The proof is complete.

Theorem 4.6 Let $E \subset X$ be a nonempty convex set, $(u, v, w) \in T\left(\operatorname{epi}\left(F_{x_{0}}, G\right), x_{0}, y_{0}, z_{0}\right)$ with $v \in C$ and $w \in D$ and $z_{0} \in G\left(x_{0}\right) \cap(-D)$. Suppose that the following conditions are satisfied:

(i) $\left(F_{x_{0}}, G\right)$ is $C \times D$-convex on $E$;

(ii) there exist $\phi \in C^{*} \backslash\{0\}$ and $\psi \in D^{*}$ such that

$$
\inf \left\{\bigcup_{(y, z) \in V} \phi(y)+\psi(z)\right\}=0 \text { and } \psi\left(z_{0}\right)=0
$$

where $U:=\bigcup_{x \in \Omega} D^{\prime \prime}\left(F_{x_{0}}, G\right)_{+}\left(x_{0}, y_{0}, z_{0}, u, v, w\right)(x)$ and $V:=\operatorname{dom}\left[D^{\prime \prime}\left(F_{x_{0}}, G\right)_{+}\left(x_{0}, y_{0}, z_{0}, u\right.\right.$, $v, w)]$.

Then $x_{0}$ is a weakly efficient solution of (CSVVEP).

Proof To prove the result by contradiction, suppose that $x_{0}$ is not a weakly efficient solution of (CSVVEP). Then there exist $x^{\prime} \in K$ and $y^{\prime} \in F\left(x_{0}, x^{\prime}\right)$ such that $y^{\prime} \in-\operatorname{int} C$. Since $x^{\prime} \in K$, there exists $z^{\prime} \in G\left(x^{\prime}\right) \cap(-D)$. It follows from assumption (i) and Proposition 3.3 that we have

$$
\left(y^{\prime}-y_{0}, z^{\prime}-z_{0}\right) \in U
$$

and then, from assumption (ii), we obtain

$$
\phi\left(y^{\prime}-y_{0}\right)+\psi\left(z^{\prime}-z_{0}\right) \geq 0
$$

Since $y^{\prime}-y_{0}=y^{\prime} \in-\operatorname{int} C, \phi \in C^{*} \backslash\{0\}, \phi\left(y^{\prime}-y_{0}\right)<0$. It follows from $z^{\prime} \in G\left(x^{\prime}\right) \cap(-D)$, $\psi \in D^{*}$, and $\psi\left(z_{0}\right)=0$ that $\psi\left(z^{\prime}-z_{0}\right) \leq 0$, thus

$$
\phi\left(y^{\prime}-y_{0}\right)+\psi\left(z^{\prime}-z_{0}\right)<0
$$

which contradicts (36). So $x_{0}$ is a weakly efficient solution of (CSVVEP), and this completes the proof.

\section{Conclusions}

In this paper, we propose a new concept of a second-order derivative for set-valued maps, which is called the second-order composed contingent epiderivative, and we investigate some of its properties. Simultaneously, by virtue of the derivative, we obtain second-order sufficient optimality conditions and necessary optimality conditions for set-valued equilibrium problems. 


\section{Competing interests}

The authors declare that they have no competing interests.

\section{Authors' contributions}

All authors read and approved the final manuscript.

\section{Author details}

${ }^{1}$ College of Sciences, Chongqing Jiaotong University, Chongqing, 400074, China. ${ }^{2}$ College of Mathematics and Statistics, Chongqing Technology and Business University, Chongqing, 400067, China.

\section{Acknowledgements}

The authors would like to thank anonymous referees for their valuable comments and suggestions, which helped to improve the paper. This research was partially supported by Science and Technology Research Project of Chongqing Municipal Education Commission (KJ130414), Chongqing Natural Science Foundation Project of CQ

CSTC(cstc2012jjA00038) and the National Natural Science Foundation of China (Nos: 11171362, 11271389, 11201509, and 11301571).

\section{Received: 15 February 2014 Accepted: 29 September 2014 Published: 16 Oct 2014}

\section{References}

1. Giannessi, F: Theorem of alternative, quadratic programs, and complementarity problem. In: Cottle, RW, Giannessi, F, Lions, JL (eds.) Variational Inequality and Complementarity Problem, pp. 151-186. Wiley, Chichester (1980)

2. Chen, $\mathrm{GY}$, Yang, $\mathrm{XQ}$ : Vector complementarity problem and its equivalence with weak minimal element in ordered spaces. J. Math. Anal. Appl. 153, 136-158 (1990)

3. Ansari, QH, Oettli, W, Schager, D: A generalization of vectorial equilibria. Math. Methods Oper. Res. 46, 147-152 (1997)

4. Bianchi, M, Hadjisavvas, N, Schaible, S: Vector equilibrium problems with generalized monotone bifunctions. J. Optim. Theory Appl. 92, 527-542 (1997)

5. Fu, J: Simultaneous vector variational inequalities and vector implicit complementarity problems. J. Optim. Theory Appl. 93, 141-151 (1997)

6. Gong, XH: Efficiency and Henig efficiency for vector equilibrium problems. J. Optim. Theory Appl. 108, 139-154 (2001)

7. Ansari, QH, Konnov, IV, Yao, JC: Characterizations of solutions for vector equilibrium problems. J. Optim. Theory Appl. $113,435-447$ (2002)

8. Kimura, K, Yao, JC: Semicontinuity of solution mappings of parametric generalized strong vector equilibrium problems. J. Ind. Manag. Optim. 4, 167-181 (2008)

9. Kimura, K, Yao, JC: Sensitivity analysis of solution mappings of parametric vector quasi-equilibrium problems. J. Glob. Optim. 41, 187-202 (2008)

10. Kimura, K, Yao, JC: Sensitivity analysis of solution mappings of parametric generalized quasi vector equilibrium problems. Taiwan. J. Math. 12, 2233-2268 (2008)

11. Kimura, K, Yao, JC: Sensitivity analysis of vector equilibrium problems. Taiwan. J. Math. 12, 649-669 (2008)

12. Gong, $\mathrm{XH}$ : Connectedness of the solution sets and scalarization for vector equilibrium problems. J. Optim. Theory Appl. 133, 151-161 (2007)

13. Gong, XH, Yao, JC: Connectedness of the set of efficient solutions for generalized systems. J. Optim. Theory Appl. 138, 189-196 (2008)

14. Gong, XH, Yao, JC: Lower semicontinuity of the set of efficient solutions for generalized systems. J. Optim. Theory Appl. 138, 197-205 (2008)

15. Giannessi, F, Mastroeni, G, Pellegrini, L: On the theory of vector optimization and variational inequalities. Image space analysis and separation. In: Vector Variational Inequalities and Vector Equilibria: Mathematical Theories, pp. 153-215. Kluwer Academic, Dordrecht (2000)

16. Morgan, J, Romaniello, M: Scalarization and Kuhn-Tucker-like conditions for weak vector generalized quasivariational inequalities. J. Optim. Theory Appl. 130, 309-316 (2006)

17. Gong, XH: Optimality conditions for vector equilibrium problems. J. Math. Anal. Appl. 342, 1455-1466 (2008)

18. Qiu, Q: Optimality conditions of globally efficient solution for vector equilibrium problems with generalized convexity. J. Inequal. Appl. 2009, Article ID 898213 (2009)

19. Gong, XH, Xiong, SQ: The optimality conditions of the convex-like vector equilibrium problems. J. Nanchang Univ., Nat. Sci. Ed. 33, 409-414 (2009) (in Chinese)

20. Long, XJ, Huang, YQ, Peng, ZY: Optimality conditions for the Henig efficient solution of vector equilibrium problems with constraints. Optim. Lett. 5(4)، 717-728 (2011)

21. Wei, ZF, Gong, XH: Kuhn-Tucker optimality conditions for vector equilibrium problems. J. Inequal. Appl. 2010, Article ID $842715(2010)$

22. Ma, BC, Gong, XH: Optimality conditions for vector equilibrium problems in normed spaces. Optimization 60, 1441-1455 (2011)

23. Aubin, JP, Frankowska, H: Set-Valued Analysis. Birkhäuser, Boston (1990)

24. Li, SJ, Zhu, SK, Teo, KL: New generalized second-order contingent epiderivatives and set-valued optimization problems. J. Optim. Theory Appl. 152(3), 587-604 (2012)

25. Jiménez, B, Novo, V: Second-order necessary conditions in set constrained differentiable vector optimization. Math. Methods Oper. Res. 58, 299-317 (2003)

26. Li, SJ, Chen, CR: Higher-order optimality conditions for Henig efficient solutions in set-valued optimization. J. Math. Anal. Appl. 323, 1184-1200 (2006)

27. Li, SJ, Teo, KL, Yang, XQ: Higher-order optimality conditions for set-valued optimization. J. Optim. Theory Appl. 137(3) 533-553 (2008)

28. Li, SJ, Teo, KL, Yang, XQ: Higher-order Mond-Weir duality for set-valued optimization. J. Comput. Appl. Math. 217(2)، 339-349 (2008) 
29. Chen, CR, Li, SJ, Teo, KL: Higher order weak epiderivatives and applications to duality and optimality conditions. Comput. Math. Appl. 57, 1389-1399 (2009)

30. Wang, QL, Li, SJ: Generalized higher-order optimality conditions for set-valued optimization under Henig efficiency. Numer. Funct. Anal. Optim. 30(7-8), 849-869 (2009)

31. Wang, QL, Li, SJ, Teo, KL: Higher-order optimality conditions for weakly efficient solutions in nonconvex set-valued optimization. Optim. Lett. 4, 425-437 (2010)

32. Jahn, J, Khan, AA, Zeilinger, P: Second-order optimality conditions in set optimization. J. Optim. Theory Appl. 125, 331-347 (2005)

33. Chen, GY, Jahn, J: Optimality conditions for set-valued optimization problems. Math. Methods Oper. Res. 48, 187-200 (1998)

34. Jahn, J: Vector Optimization-Theory, Applications and Extensions. Springer, Berlin (2004)

35. Corley, HW: Existence and Lagrangian duality for maximization of set-valued functions. J. Optim. Theory Appl. 54, 489-501 (1987)

36. Aubin, JP, Ekeland, I: Applied Nonlinear Analysis. Wiley, New York (1984)

37. Jiménez, B, Novo, V: Optimality conditions in differentiable vector optimization via second-order tangent sets. Appl. Math. Optim. 49, 123-144 (2004)

10.1186/1029-242X-2014-406

Cite this article as: Wang et al.: Second-order composed contingent epiderivatives and set-valued vector equilibrium problems. Journal of Inequalities and Applications 2014, 2014:406

\section{Submit your manuscript to a SpringerOpen ${ }^{\ominus}$ journal and benefit from:}

- Convenient online submission

Rigorous peer review

- Immediate publication on acceptance

- Open access: articles freely available online

- High visibility within the field

- Retaining the copyright to your article 